\title{
The Feminist Case Against Relational Autonomy
}

\author{
Serene J. Khader \\ cuNY Graduate Center, Brooklyn College, New York City, NY, United States \\ sjkhader@brooklyn.cuny.edu
}

\begin{abstract}
Feminist socially constitutive conceptions of autonomy make the presence of idealized social conditions necessary for autonomy. I argue that such conceptions cannot, when applied under nonideal conditions, play two key feminist theoretical roles for autonomy: the roles of anti-oppressive character ideal and paternalismlimiting concept. Instead, they prescribe action that reinforces oppression. Treated as character ideals, socially constitutive conceptions of autonomy ask agents living under nonideal ones to engage in self-harm or self-subordination. Moreover, conceptions of autonomy that make idealized social conditions a requirement of autonomy yield the conclusion that oppressed agents are appropriate objects of paternalism.
\end{abstract}

\section{Keywords}

autonomy - oppression - nonideal theory - feminist philosophy - relational autonomy - moral psychology

Oppressed agents face inducements to perpetuate, and internalize the norms behind, the social order that subjugates them. Oppressed agents also negotiate and resist. Feminists need a conception of autonomy that acknowledges both sets of facts. Feminist socially constitutive conceptions of autonomy (see Oshana 1998, Stoljar 2014, Mackenzie 2015, Gauthier-Chung 2017), sometimes referred to merely as "relational conceptions of autonomy," attempt to make sense of the facts by suggesting that the mere fact of having to resist or negotiate is evidence of compromised autonomy. According to feminist socially constitutive conceptions of autonomy (hereafter SCA), oppressive conditions limit self-direction. 
Most arguments that feminists should adopt SCA rely heavily on conceptual analysis. This would be fine if feminist theorists shared intuitions about autonomy under oppression. Unfortunately, we do not. The victim of racism who joins anti-racist movements is for some an autonomy exemplar (Meyers 20oob; Khader 2011; Noggle 2011), and for others a central example of its diminishment (Oshana 2015). The woman who reflectively endorses the belief that wives should be submissive elicits in some the judgment that traditional lives can be autonomous (Meyers 1987; Christman 2004; Friedman 2006; Khader 2011), but to others constitutes a reductio of conceptions of autonomy that would permit such a conclusion (Stoljar 2000; Westlund 2003; MacKenzie 2008).

Figuring out how feminists should conceive autonomy thus requires doing more than consulting intuitions. Rather than attempting to adjudicate among competing intuitions, I propose here that we ask how well SCA do at doing what feminist philosophers want autonomy to do. Feminists want moral and political concepts to help diagnose oppression and offer guidance about how to alleviate it. Given this, two important feminist roles for the concept of autonomy are those of character ideal and paternalism-limiting concept. I argue that sCA cannot play these roles well. Because feminist SCA make idealized ${ }^{1}$ social conditions a requirement of autonomy, their prescriptions about actual, nonideal conditions are perverse - that is, they exacerbate the oppression and vulnerability of oppressed agents. Character ideals that prescribe behavior that promotes equality and well-being under idealized social conditions promote self-subordination and self-harm under nonideal ones. When the presence of idealized social conditions is understood as a requirement of autonomy, oppressed agents become legitimate targets of promiscuous paternalism.

Since my argument rests on a certain view of the theoretical roles of autonomy in feminist philosophy, and a nonideal theoretical understanding of what feminist philosophy is, I begin by making explicit what I take to be at stake in feminist conception choice with regard to autonomy. Readers who believe that feminists should seek conceptions of autonomy that can furnish anti-oppressive character ideals and who see oppression concerns as demanding circumspection about hard paternalism toward oppressed persons need not dwell in this first section. In the second part of the article, I explain what SCA are. In the third and fourth sections, respectively, I explain how SCA, in the roles of character ideal and paternalism-limiting concept, yield perverse conclusions. Readers who are familiar with my criticisms of socially constitutive and

1 I use the term "idealized" rather than "ideal," because sca need not hold that autonomy requires utopian conditions; most hold only that autonomy requires social conditions that meet some moral standard that oppressive conditions do not. 
substantive autonomy in my work on adaptive preferences $(2011,74-107 ; 2012)$ can also read this article as developing the theoretical underpinnings of my criticism of the latter and responding to those who have attempted to rehabilitate substantive authority in ways that withstand my criticisms.

\section{What Feminists Want From a Conception of Autonomy}

My argument against socially constitutive autonomy rests on three related ideas about what makes a conception of autonomy worthy of adoption by feminists: that autonomy is a concept designed to serve certain theoretical roles, that feminists have specific interests in its ability to serve the roles of anti-oppressive character ideal and paternalism-limiting concept, and that these interests arise from feminist philosophy's nonideal theoretical character. As Diana Meyers notes, autonomy talk is present in everyday life in discussions of being true to ourselves, knowing what we really want, feeling right in our skin, and so on (Meyers 20oob: 151). Though this is true, autonomy judgments do more than capture intuitions about individuals' authenticity and self-direction. "Autonomy" is a philosophical "term of art" that is irreducibly "connected with other notions" and plays a "role in justifying normative claims" (Dworkin 1988: 7) within liberal theories. Autonomy ascriptions carry with them judgments about the moral status of persons and preferences.

Feminists should care whether the normative prescriptions that result from plugging autonomy into these roles are consistent with anti-oppressive aims. Caring about the prescriptions that result from defining concepts in certain ways is part of reflective equilibrium and not unique to feminist philosophy. ${ }^{2}$ But feminists want prescriptions that expose the badness of oppression and guide action that opposes it.

On this description, feminist philosophy is at least partly a nonideal theoretical enterprise. Nonideal theory, in the sense developed by Charles Mills (Mills 2005; Mills and Pateman 2007) and Amartya Sen (2009), refers to theory

2 Other examples of arguments and claims that assume that the prescriptions generated by adopting concepts and theories are germane to whether we should adopt them include the self-effacingness objection to consequentialism, Rawls' (1991) claim that a conception of justice should be public and capable of guiding the development and reform of a society's political institutions, and Pettit's (2002) discussion of the reasons why a republican conception of freedom should be chosen over the alternatives. See Lindauer (2019) for a discussion of these examples and a broader argument that the practical effects of adopting concepts can matter inevaluating concepts and choosing between them. 
that provides normative guidance about how to decrease injustice. ${ }^{3}$ Feminist philosophy will fall foul of its own theoretical desiderata if it prescribes behavior that, in the world we actually inhabit, ends up retrenching oppression (see Walker 2007; Haslanger 2005). My key claim in this paper will be that SCA contravene feminist commitments in just this way when plugged into the roles of character ideal and paternalism-limiting concept. ${ }^{4}$ These roles overlap with roles which liberals ascribe to autonomy, but, as we shall see, feminists have distinctive reasons for assigning importance to them.

\subsection{Autonomy as Feminist Character Ideal}

One important role of the concept of autonomy is to name the desirable character trait or type associated with being self-determining. Feminists may or may not share antecedent commitments to the type of comprehensive liberalism that takes self-determination to derive its value from a concept of human flourishing (see Raz 1988, Mill 2008). Distinctively feminist valorization of autonomy as a character ideal has to do with three ways autonomy in individual agents contributes to feminist ends. First, people with autonomous characters are more likely to question the acceptability of their oppression (see Meyers 1991; Oshana 2006: 58; Wollestonecraft $\left.1996^{5}\right)$. For example, women who are socialized primarily to be caregivers are socialized to be "dependent on others for approval and direction" (Meyers 1987: 621). Cultivating the desire to release oneself from oppressive roles means developing autonomy skills such as the ability to imagine oneself occupying different social roles (see also Mackenzie 2002) and the ability to attune oneself to, and to take seriously, felt dissatisfaction with unjust social conditions.

Second, autonomy may help agents, not just criticize, but also reduce their subjection to, oppression. Because autonomous persons are deeply in touch with what they value, they are adept at identifying their own interests and detecting attempts to dominate them. Autonomy thus authenticates attempts by oppressed individuals to distinguish their interests from those of their dominators (Oshana 2006:141) and stand up for their interests in political life (Oshana 2014; Oshana 2006: 130-131; Christman 2004, 152). It may also allow women to notice when they are being dominated by men (Friedman 2006:18-19).

Third, it is sometimes argued that autonomous lives express feminist values. If oppression is wrong partly because it treats members of some social groups

3 More often than prescribing behavior that impedes the achievement of justice, ideal theories are silent on questions about what to do in the transition from nonideal to ideal conditions (see Mills 2005).

4 I put aside two other oft-discussed feminist roles for autonomy: consent validation and the attribution of moral responsibility, because questions about these are typically thought to be practice-specific.

5 See Mackenzie 2017 for a reading of Wollestonecraft as a relational autonomy theorist. 
as vehicles for the fulfillment of the aims of others, autonomous lives express opposition to oppression (Friedman 2006: 4; Beauvoir 2011).

\subsection{Autonomy as Paternalism-Limiting Concept}

Limiting paternalism is the distinctive role of autonomy in moral and political theories (Dworkin 1988), and feminists should care about what a given conception of autonomy implies about paternalism. Feminists advocate social change, and the right conception of autonomy will clarify the range of cases where paternalistic means to such change are acceptable, as well as differentiate acceptable and unacceptable means of change. Since the idea that feminists should be circumspect about paternalism may surprise some, I pause to motivate it. After all, a common (and, in my view, correct) feminist argument is that the fetishization of noninterference that characterizes some liberal views protect men's interests at the expense of women's (MacKinnon 1991). Moreover, the fact that oppressed individuals internalize their oppression may seem to justify overriding their wills. However, most feminists ${ }^{6}$ who acknowledge these facts typically argue against hard paternalism and advocate political strategies that acknowledge and respect women's agency ${ }^{7}$ or autonomy (see Meyers 20ooa; Narayan 2002; Khader 2011, 2012; Lugones 2003a; Lugones 2003b; Christman 2004; Mahmood 2005; Friedman 2006; Laborde 2008; Madhok, Phillips et al. 2013). Rather than being motivated by belief in the intrinsic value of noninterference, feminist caution about coercion and other hard ${ }^{8}$ paternalism stems primarily from concerns about worsening the condition of the oppressed.

One way that overriding the wills of the oppressed might worsen their condition is by entrenching oppressive systems or exacerbating the effects of oppression on individuals. Oppressive systems function in sufficiently complex ways that strategies that reduce oppression in one domain of life may increase it in others, at least for certain persons. Distinct systems of oppression can also intersect such that reducing the power of one oppression over an individual increases her subjection to other oppressions (Crenshaw 1991). So, for example, strategies to reduce sexism by restricting engagement in beauty practices

6 A notable exception to this trend of rejecting hard paternalism is Clare Chambers (2004, 2008), who supports a ban on breast implants. Chambers' ban is subject to the criticisms I make in the paternalism section. See Laimann (2015) for a response to Chambers in a similar vein.

7 See Madhok and Phillips $\left(2013,5^{-8}\right)$ for a discussion of the meanings of the terms "autonomy" and "agency" in feminist theory and an argument for why they are less different than they initially seem.

8 Hard paternalism (Sunstein 1999) is paternalism that attaches high costs to an agent's chosen course of action. 
might reduce the gender oppression of women with disabilities while worsening their subjection to ableist oppression, since they lose an opportunity to resist cultural practices that render them invisible and represent them as lacking in sexuality (Oliver 1990; Widdows 2018). Hard paternalistic anti-oppressive measures can also end up entrenching oppression by expressing and contributing to the view that oppressed people are poor judges of their own interests. To continue with the above example, restrictions on participation in beauty practices might retrench views that women need men to make decisions for them, because women are stupid or preoccupied with trivialities.

Paternalism can also directly increase the subjection of the oppressed to the wills of the dominant. In societies where it is widely assumed that individuals from oppressed groups are bad knowers or morally defective, paternalistic interventions can enact epistemic oppression (see Dotson 2014). Since it may be difficult for public institutions to detect in advance how putatively feminist strategies will increase some individuals' vulnerabilities, and because affected individuals are especially well-situated to know how proposed changes will affect them, a presumption in favor of respecting autonomy can prevent well-intentioned political strategies from exacerbating the effects of oppression.

A second reason why feminists want to limit paternalism is that paternalistic strategies can reduce the well-being (rather than increase the oppression) of oppressed individuals. This is because women can have what Uma Narayan (2002) calls "real stakes" in the continuation of oppressive orders. Because they rely on complying with oppressive norms to attain well-being, and because new conditions of accessing well-being are often unlikely to emerge in the short term, an individual woman can stand to incur costs as a result of genuinely anti-oppressive strategies (see Khader 2018: 71-75). Narayan's example of what Kandiyoti (1980) famously called "bargaining with patriarchy" involves women who practice body veiling partly because they depend on income from a shrine whose marketability depends on the women's visible purity; eliminating the shrine would have demonstrable negative effects on these women. Besides impeding self-protective bargaining with patriarchy, another way feminist paternalism risks reducing the well-being of oppressed individuals is by preventing those with deeply internalized oppression from pursuing what they genuinely value (see Christman 2004: 158).

A third reason why feminists should avoid paternalism is that ignoring the voices of oppressed individuals can impede feminist social change. As John Christman (2004) argues, ignoring the values of women and other marginalized people may be flatly inconsistent with the aims of feminism. Even if a change is motivated by genuinely feminist values, not all strategies for implementing it are equally likely to be effective or equally likely to be endorsed. As I have argued elsewhere, women and other oppressed individuals are less 
likely to participate in or endorse strategies for social change that impose high costs on them (Khader 2011; 2018: 71-75). Additionally, it may be difficult to figure out what the specific harms imposed by a social order are, or what should be done about them, without consulting those who are affected (see Khader 2011). As standpoint theorists argue, many oppressed individuals experience conflict between what they want and what the social order makes possible. Because of this lived friction, oppressed individuals are especially skilled at identifying problems with oppressive social institutions (see Collins 200o) and can provide invaluable input about the types of social changes that are needed.

To sum up the above reasons why feminists should be circumspect about hard paternalism: what seems like oppressed people being mistaken about what would improve their lives is often their making correct judgments about the effects of social change on them, effects that others who do not occupy their social positions have difficulty detecting (see Narayan 2002: 425-429; Khader 2011). A presumption against hard paternalism makes it possible for societies to register resistance to misguided attempts at feminist social change. The reasons behind such resistance can provide valuable information for designing strategies for change, but this information will be lost if resistance is overlooked or not registered as resistance.

\section{Defining Socially Constitutive Conceptions of Autonomy}

Before arguing that socially constitutive conceptions of autonomy, when plugged into feminist roles, offer perverse character prescriptions and permit too much paternalism, I pause to explain what socially constitutive conceptions of autonomy are. Social constitutivity is a type of externalism in which the external conditions that make up autonomy are features of social and political orders. This paper discusses feminist SCA, namely those that hold that autonomy consists in the presence of social conditions with more access to well-being or equality than real-world oppressed agents actually have.

My characterization excludes some conceptions that might be thought of as socially constitutive. First, it excludes conceptions that are socially constitutive only insofar as they take autonomy to be constituted by dispositions that must be exercised with others, such as Andrea Westlund's (2009) dialogical answerability ${ }^{9}$ conception. Second, it excludes conceptions that take morally

9 Westlund argues that her account does not map onto the internalist/externalist distinction, but $(2009,34)$ I think her account is best described as internalist, since she does not take autonomy to be constituted by answerability to actual other agents. An interpretation of her 
bad or arbitrary social conditions, or social conditions that are unrelated to oppression, as prerequisites for autonomy. I do not address such conceptions because they would be unlikely to do feminist philosophical work. Only conceptions that make external components of well-being or equality, or opportunities for them, into elements of autonomy are likely to appear helpful for anti-oppressive theorizing. Since my argument here targets the structural features of SCA, I will not focus on any single conception of autonomy in what follows.

However, to give the reader a sense of what the details of SCA look like, I describe some existing conceptions. ${ }^{10}$ Marina Oshana argues that autonomy requires the ability to pursue goals which are different from those of one's dominators (1998: 93-94), enough options to not be coerced into caring for others, and access to a wide range of rights and options (2006). Natalie Stoljar argues in recent work (2014) that autonomous agents must inhabit social conditions where they can contravene oppressive norms without loss. Maud Gauthier-Chung (2017) argues that the autonomy that matters for practical purposes consists entirely ${ }^{11}$ in the presence of equal access to opportunities to achieve well-being.

Since it has become a truism that feminists should advocate "relational" autonomy, it is worth specifying the sense in which SCA are relational. Some advocates of SCA, such as Oshana, treat SCA and "relational autonomy" as synonyms, and it is this usage that has caused me to refer to "relational autonomy" in general in the title of the paper. However, there is a broader use of the term "relational autonomy" among feminists, wherein "relational" refers to conceptions of autonomy that acknowledge the effects of socialization and subjection to power on the self (Mackenzie and Stoljar 2001: 21-22). Lack of relationality is also often ascribed to conceptions of autonomy that deny that autonomous persons can value, and be formed through, attachments to others. SCA are not the only conceptions of autonomy that can be relational in these senses. For example, an internalist conception of autonomy might hold that reflection on one's desires is sufficient for autonomy and still meet criteria for relationality. Such a conception could allow that some forms of socialization are especially

account that took answerability to actual agents to be constitutive of autonomy would be vulnerable to the criticisms I make here.

Additional socially constitutive conceptions can be found in Mackenzie (2015) and (albeit a nonfeminist one) in Raz (1985). Raz suggests at one point that options are not constitutive of autonomy, but his well-known example of the hounded woman seems designed to highlight the flaws of nonconstitutive conceptions.

11 Gauthier-Chung's view is that the kind of autonomy that matters for political praxis consists entirely in opportunities. See also the footnote below. 
compatible with reflection and hold that caring deeply about others can be reflectively endorsed.

SCA advocates' tendency to limit the term "relational autonomy" to SCA notwithstanding, SCA go beyond acknowledging the importance of the social. On SCA, social conditions do not merely help individuals develop autonomous internal characteristics; the agent's autonomy comprises certain social conditions. In regard to SCA, two individuals with identical psychic constitutions but different conditions can have different autonomy statuses. An example from Oshana (2006) highlights this idea: two women might endorse being submissive housewives through the same psychological processes but one may live in a society with no exit options. SCA permit the conclusion that the woman who lives in the more just society is more autonomous.

SCA can vary in degree of social constitutivity. Some, such as Maude Gauthier-Chung's (Gauthier-Chung 2017a; Gauthier-Chung 2017b), say that social conditions constitute the entirety of an agent's autonomy. ${ }^{12}$ Other SCA are hybrid conceptions that say that there are internal requirements for autonomy in addition to external ones. Some SCA are very demanding about how just the external conditions constitutive of autonomy must be (Raz 1988; Oshana 1998, 2015), where others are less clear and potentially less demanding (Mackenzie 2015). Irrespective of this variation, social constitutivity causes feminist conceptions of autonomy, when applied to our nonideal world, to produce some degree of the perverse consequences described below.

Since a somewhat orthogonal feature of conceptions of autonomy, namely substantiveness, has taken center stage in feminist conversation, it is worth distinguishing social constitutivity from it. Much existing debate concerns whether feminists should adopt substantive conceptions (see Meyers 1991; Stoljar 2000; Narayan 2002; Christman 2004; Khader 2011; Sperry 2013) - that is, conceptions that say that autonomous preferences must have certain contents (as opposed to procedural ones that say autonomous preferences must be arrived at by certain processes). Procedurality and substantiveness both refer to internal components of autonomy - that is, preference content or psychological processes. Since social conditions are external to the agent, SCA can be procedural, substantive, or simply deny that autonomy has internal

12 Gauthier-Chung argues that psychological capacities count conceptually as components of autonomy, but that it is practically desirable to assume that everyone has the relevant psychological capacities. The subset of my paternalism criticisms later in the paper about assuming diminished psychological capacity of the oppressed do not apply to her account as stated. However, her account is especially vulnerable to all of my other criticisms of $\mathrm{SCA}$, given that it severs autonomy from character and reduces autonomy to the presence of opportunity. 
components. However, as we will see in the next section, only SCA that are substantive are amenable to doing some of the work feminists want conceptions of autonomy to do, that is, functioning as character ideals. I will show in the next section that, when asked to perform this function, the feminist problems with SCA go beyond those associated with internalist substantive conceptions.

\section{Problems with Socially Constitutive Autonomy as a Character Ideal}

Employed in the role of character ideal, sCA end up prescribing that oppressed individuals should a) harm themselves or b) perpetuate their own oppression - unless they c) end up not being action-guiding under nonideal conditions at all. Before I make these points, it is worth noting that the very structure of SCA makes them ill-suited to be character ideals. Character ideals cover agents' attitudes, dispositions and behaviors. Social conditions on their own do not prescribe action or reasons for action.

Another problem arises from the fact that what SCA take to be external components of autonomy can be present without affecting agents' behavior or attitudes. Since the presence of an opportunity to engage in a behavior is consistent with both engagement and nonengagement in it, some SCA do not prescribe any behavior at all.

\subsection{Substantive Socially Constitutive Conceptions}

The subset of socially constitutive conceptions or autonomy that are capable of functioning as prescriptive character ideals will also be substantive. Not all existing socially constitutive conceptions are substantive. For example, Natalie Stoljar suggests a nonsubstantive socially constitutive conception in the parts of her work where she claims autonomy requires options that would permit "freedom to do otherwise" than following oppressive norms (2014). ${ }^{13}$ Nonsubstantive socially constitutive conceptions like this one can only tell agents what their social conditions should be like - not what they should do, and they are thus ill-suited to be character ideals.

In an important paper, John Christman (2004:150-151) criticizes substantive socially constitutive conceptions of autonomy for being substantive. He argues that substantive socially constitutive conceptions proceed from judgments about what an autonomous life looks like to claims about the options necessary for this life. Because SCA include perfectionist content, they invalidate the choices of individuals who choose the "wrong" kinds of lives. Christman

13 Stoljar's earlier work (see 2002) argues for a substantive conception of autonomy rather than a nonsubstantive socially constitutive conception. 
is right, but this problem accompanies all substantive conceptions of autonomy - that is, all conceptions that say that autonomous preferences must have certain content. I am about to argue that substantive SCA (hereafter SSCA), by virtue of their externalism, pose problems besides substantiveness when we attempt to treat them as character ideals. sscA do not merely tell agents they must act a certain way to live autonomously; they say that agents should take advantage of the opportunities constitutive of autonomy. Oppressed agents, however, live under conditions where at least some such opportunities are absent. As a result, SSCA either say that oppressed agents should either act as though the opportunities constitutive of autonomy were present or end up saying nothing about what oppressed agents should do.

Feminists want the character ideal of autonomy to guide women to participate in anti-oppressive struggles, or at least act in ways that reduces the harms oppression visits on them. Saying nothing about what oppressed agents should do clearly falls short of offering an anti-oppressive character ideal. But what about the first strategy - that of telling oppressed agents to act as though they live under conditions where better opportunities were present? To see what is wrong with prescribing that oppressed agents should act as though they lived under idealized conditions, we need to note something that is entailed by feminist reasons for wanting to treat autonomy as a character ideal. Behavior that opposes oppression or reduces the effects of oppression on an individual has to be behavior with means-end effectiveness. However, behaviors that would be means to achieving well-being or promoting equality under just conditions can become means to harm or the perpetuation under oppressive ones.

\subsection{The Tragic Structure of Oppressed Agents' Options}

To understand how an oppressed individual's acting as though she lives in an idealized world is likely to visit harm or further oppression on her, we need to bring some facts about our nonideal world into view. Specifically, we need to see that oppressed individuals face option sets with a tragic structure. As I have argued elsewhere, oppressed agents are often forced to choose between promoting their well-being and opposing the subordination of their group (Khader 2014; 2016; forthcoming). An example will illustrate this. Lydia is an attorney who is a woman of color. Like most women working in white collar environments, she is expected to fulfill the "professional beauty qualification" (Wolf 2002) and to be hyper-agreeable. Maintaining a certain body shape, wearing expensive clothing, straightening her hair and other cumbersome beauty treatments help her be perceived as competent. Asserting her interests selectively and indirectly helps her manage perceptions that she is aggressive. She may receive better cases because she is perceived as more qualified; white colleagues and clients may be less likely to racially stereotype her as hostile 
because she acts and appears more pleasing; and she may accrue raises and promotions because she is thought to be a team-player and because caring about her appearance is thought to bespeak caring about her job. Men do not face the same expectations, and white women do not face them in the same way. Beauty-related pursuits demand time, money, and energy, and agreeability demands emotional suppression.

Refusing to comply with these oppressive norms would likely reduce Lydia's ability to achieve her professional goals (and gain other important goods that come from employment), but complying does nothing to change, and perhaps even reinforces, the expectation that women, and women of color in particular, should engage in oppressive beauty practices. If it seems paradoxical to claim that something can be both oppressive and well-being enhancing, it may help to keep two facts in mind. First, to say that something is well-being enhancing, or even that it is the most well-being enhancing option, is only to rank available options; it involves no claim about the acceptability of the menu. Second, oppression is definitionally a condition that structures the relationship of social groups to each other (see Frye 1983). ${ }^{14}$ To be oppressive, a social order does not need to remove opportunities for well-being from the oppressed; it needs only offer worse opportunities than it offers the dominant.

We can think of oppressed agents as facing a dilemma with two prongs: choose well-being through self-subordination, or choose opposition to oppression through self-sacrifice. SSCA, taken as an action-guiding character ideal under nonideal conditions, unacceptably prescribe that oppressed agents choose one of the prongs. Which prong depends on how a given conception specifies the social conditions necessary for autonomy. It depends on whether the social conditions required for autonomy amount to increased availability of what is already valuable in a given context or access to a social order that does not require some groups of people to subordinate themselves to increase their well-being. If a given substantive socially constitutive conception of autonomy specifies opportunities context-relatively (as in the case of Gauthier-Chung 2017b), it prescribes self-subordination; if it specifies them aspirationally (as in the case of Oshana 2006), it prescribes self-sacrifice. In the former case sscA prescribe the perpetuation of oppression and in the latter, sscA endorse oppressive values at the theoretical level and unduly burden oppressed agents with responsibility for ending oppression.

14 According to Frye's (1983) definition, oppression describes structural conditions that disadvantage certain social groups in order to benefit others. 


\subsection{Context-Relative ssca Prescribe Self-Subordination}

Gauthier-Chung conceives autonomy as requiring "options that are determined contextually within a given time and society" (2017b: 87 ). Though she does not conceive autonomy as a character ideal, this part of her view gives an example of how one might specify the social conditions constitutive of autonomy in a context-relative fashion. One might think that the external conditions necessary for autonomy comprise greater quantities of the opportunities that already advance the well-being of oppressed persons within a given context. In just societies, the opportunities that promote well-being will be those whose exercise is consistent with social equality. But in unjust contexts like Lydia's, morally repugnant or self-subordinating opportunities can become means to well-being.

Context-relative sSCA, applied as character ideals for oppressed agents, ask agents like Lydia to reinforce their own subordination. In regard to context-relative SSCA that took opportunities for professional success to constitute autonomy, Lydia's engagement in oppressive beauty practices would be required for autonomous action. If SSCA were thought of as a feminist character ideal, then something further would follow: oppressive beauty norm compliance would exhibit anti-oppressive virtues. To put the point independently of the example: in oppressive contexts, character ideals based on context-relative SSCA prescribe self-subordination because self-subordination is a means to well-being in oppressive contexts (see Khader 2014; forthcoming). But this prescription should strike feminists who think the character trait of autonomy is supposed to help women resist oppression as perverse.

There is another, less direct way character ideals based on context-relative SSCA are at odds with anti-oppressive aims. They treat the values of the dominant as morally correct. As Iris Marion Young (Young 1991) argues, oppressive societies do not merely distribute goods differentially; they also determine what counts as a good in prejudicial ways. Lydia's society treats the attractiveness and sexual availability of women as good, but these goods promote patriarchal dominance. It is true that Lydia stands to benefit materially from embracing patriarchal and racist values. But surely feminists should be skeptical about character ideals that treat these values as morally correct. Encouraging oppressed agents to invest in value systems that downgrade their values just because oppressed agents' values already happen to be downgraded is in tension with feminist aims. As Lisa Tessman argues (175-198), building the demands of nonideal circumstances into our normative concepts jeopardizes our ability to assign moral value to the creation of a world without oppression. 


\subsection{Aspirational Conceptions Prescribe Self-Sacrifice}

The solution to these problems may seem to be to build the presence of less oppressive conditions for well-being into autonomy. What I am calling "aspirational" SSCA solve the problem of prescribing self-subordination by making something like the ability to function in society as an equal a requirement for autonomy. For example, Oshana (2006) argues that agents need equal opportunities and nondomination to be autonomous. Such conceptions, when treated as action-guiding character ideals, recommend that oppressed agents should act as though they lived in societies that recognized their equal status.

However, prescribing that oppressed agents act as though they could access well-being without self-subordination amounts to asking them to court selfharm. Because of the tragic structure of oppressed agents' options, flouting oppressive norms often means exposing oneself to penalties. Consider Oshana's view that autonomy requires the absence of the expectation that one take responsibility for the needs and expectations of others (Oshana 1998: 94). Data on emotional labor show that, in our nonideal world, women who refuse to take responsibility for the needs and expectations of others are punished (Bowles et. al 2007; Williams 2007). Lydia may decide to act as though the professional beauty qualification and others' racial discomfort with her did not need to be managed, but she would pay a price. If the price in the example seems low, consider similarly structured situations where it would be high; acting as though there are no penalties for reporting sexual harassment might cause job loss, acting as though one is not vulnerable to criminalization because of one's race can increase one's vulnerability to violence, and so on.

It is unclear how courting self-harm in the way a character ideal based on ssca would recommend could be the only fitting way to enact resistance to oppression. Seeing something wrong with one's oppression does not entail that one should act as though one is not oppressed. Moreover, an individual who acts as though oppressive norms are absent is unlikely to reduce the effects of those norms on the world, or on her. Norm change typically requires collective action that challenges barriers, not individual behavior that ignores them.

It might be objected that morality is hard and feminist social change just requires self-sacrifice - that the oppressed agent who acts as though the world were better expresses feminist values in spite of courting harm. But commitments to opposing oppression militate against victim-blaming and assigning the burdens of ending oppression disproportionately to victims. It is incumbent on the defender of a prescription that oppressed agents engage in self-sacrifice to explain why it is expressive of feminist values to recommend that victims of oppression make their lives worse than they already are. 


\subsection{An Objection: Non-Substantive scA as Character Ideals}

The socially constitutive theorist may object that my discussion in this section began from a mistaken assumption - namely that only substantive sCA could function as character ideals. After all, SCA state only that certain opportunities must be available, and opportunities are not requirements. It may thus seem that SCA could function as character ideals without being substantive in the following way: the presence of opportunities might enable behavior that is positively correlated with reflecting upon and rejecting oppression. To use our existing example, one might fill out the content of socially constitutive autonomy to include external opportunities that help an agent detect what she wants and pursue it, as in, say the view that the opportunity to be free of the professional beauty qualification would make it easier for Lydia to decide just how much she cares about beauty. Or, one might claim that the presence of options enables autonomous behavior by adding desired options to agents' sets. So, for example, Lydia may want to be free of the professional beauty qualification, so the opportunity to be free of it just helps her do what she wants to do.

I reply that these enabling views are highly plausible but that the conceptions of autonomy that underlie them are not socially constitutive. If the view is that an agent's capacities for autonomous reflection are enabled by external conditions, we have an internalist view rather than a socially constitutive conception of autonomy. If it is that an agent's ability to do what she wants is enhanced by the presence of desired options, we only have an explanation of how options enhance the autonomy of agents who already want them. In both cases, the link between autonomy and external social conditions is contingent and empirical rather than constitutive - contingent in the first case on what helps an agent critically reflect (presumably some agents could reflect adequately absent the social conditions) and in the latter case on the desires of existing agents.

If we try to save the last version of the enabling view - the one that says that improved social conditions enhance autonomy by offering desired options - by claiming that autonomous behavior is enabled regardless of what the agent desires, we either lapse into SSCA and the attendant problems I have just discussed or sever the link between autonomy and character. Character ideals are supposed to provide reasons for action, but the only reasons that the modified enabling view can give to the person who does not want enhanced options are the objective moral reasons characteristic of substantive conceptions of autonomy. If we say that a person's autonomy is enabled through conditions that do not give her any kind of reasons, autonomy seems conceptually redundant. As I will discuss at greater length in the discussion of paternalism below, we already 
have the distinct concept of opportunity, and it is unclear what is added by calling opportunities "autonomy." In fact, if the arguments about paternalism I make in the next section are correct, calling opportunities "autonomy" introduces significant theoretical disadvantages.

\section{Problems with Socially Constitutive Autonomy as Paternalism-Limiting Concept}

SCA do not only offer perverse prescriptions when treated as character ideals. They also prescribe political strategies that exacerbate oppression. Because they make the presence of idealized conditions a prerequisite for autonomy, feminist SCA take oppressed agents to possess diminished autonomy. SCA advocates see this entailment as a strength. But the view that oppressed agents lack autonomy is a liability when it comes to political praxis under nonideal conditions. In regard to SCA, paternalism that worsens the condition of oppressed agents may seem morally acceptable, or even required. The reasons for this excessive paternalism tolerance are triple: SCA imply that the oppressed are relatively less autonomous than the dominant, they remove the principled reason for refusing to coerce oppressed individuals, and they obscure the costs option that enhancement can impose under nonideal conditions.

The threat of justifying these types of paternalism attends all feminist SCA, because all such views entail that the oppressed are less autonomous, at least with respect to the external components of autonomy, than the dominant. Though many defenders of sCA attempt to stave off these paternalism implications, their strategies for doing so involve creating somewhat idiosyncratic, and sometimes ad hoc, conceptual architectures around autonomy. Because of this, I direct the paternalism criticisms below against SCA in general, and introduce the views of particular advocates of SCA in elaborating more sophisticated strategies for staving off my criticisms.

\subsection{Nonreciprocal Vulnerability of Oppressed Agents to Paternalism}

Part of oppression is domination. As Young (1991) argues, oppressed groups find themselves subject to the will of the powerful. This domination often takes the form of paternalism, justified by the claim that the oppressed need the dominant to make decisions for them. A key paternalism-related issue that all feminist SCA pose is that they seem provide support for this claim by implying that the oppressed are less autonomous than the dominant. If autonomy entitles one to having decision-making authority in one's own life, and if autonomy consists partly in access to morally desirable social conditions, oppressed 
individuals will have a lesser entitlement to making decisions about their own lives than the dominant do over theirs. This unequal entitlement to autonomy is a distinctive feature of SCA, since SCA make the thing that oppressed agents lack and dominant agents have (namely, a social context that does not oppress one) a constitutive feature of autonomy.

Besides being intuitively noxious, this implication about the relative autonomy of members of dominant and nondominant groups promotes disrespect for oppressed people's choices as Christman (2009) argues. In addition to directly justifying such disrespect, SCA are likely to offer a (seemingly feminist) moral justification for epistemic oppression. The idea that oppressed people are less self-directed than the dominant supports subjecting their views, testimony, and decisions to greater scrutiny and suspicion than those of the dominant.

Defenders of SCA may offer two objections to my view that SCA increase the vulnerability of the oppressed to paternalistic forms of domination. First, defenders of hybrid internal-external views, such as Oshana (2006) and Mackenzie (2014), may deny that SCA yield the view that the dominant are more autonomous on the grounds that the oppressed are advantaged with respect to some elements of autonomy - just not those that take the form of external social conditions. I address this objection in more detail in my discussion of internally differentiated hybrid conceptions below. For now, I merely note that it is unclear what these domains of autonomy in which the oppressed had enhanced self-direction would be, and that this objection rests on showing, not just that the oppressed can have superior internal autonomy, but that they have it systematically. This needs to be shown because the autonomy deficit oppressed people have on feminist SCA is systematic and definitional; oppressed people lack the social conditions constitutive of autonomy just by virtue of being oppressed.

Second, defenders of SCA might raise Oshana's objection (2006: 100) that socially constitutive conceptions of autonomy do not do anything to oppressed individuals, as it is social conditions and not concepts that cause this diminishment. This objection misses the fact that moral concepts do more than describe reality. When there are competing reasonable conceptions of moral and political concepts, we have some discretion over which conceptions to adopt. An important consideration, especially for feminists, is what will happen in the world if we choose certain concepts, or conceptions of these concepts, rather than others (Haslanger 2005; Mills 2005, Walker 2007). ${ }^{15}$ It is

15 In addition to having a long history in feminist philosophy, the idea that conception choice should be affected by practical implications, is the topic of much discussion in the 
clear that paternalistic domination in the world has both philosophical and material causes. However, adopting SCA makes continued paternalistic domination appear morally justified, and this should count as a strike against SCA.

\subsection{Paternalistic Coercion of Oppressed Individuals}

So SCA, when adopted, lend support to moving decision-making authority out of the hands of the oppressed and into the hands of the dominant. As I argued at length in Adaptive Preferences and Women's Empowerment, incorporating socially constitutive content into autonomy lends support to paternalistic coercion of the oppressed. SCA do this is by making the best-known principled argument against coercive paternalism unavailable in oppression cases. It is usually argued that paternalistic coercion is wrong because it violates the autonomy of the coerced. But the idea that opportunities are constitutive of autonomy introduces the possibility that people who lack them are not autonomous, or not autonomous enough. This potential to support paternalistic coercion of the oppressed is a problem for all conceptions of autonomy on which the oppressed possess diminished autonomy, but SCA support such coercion across a particularly wide swath of cases, because, SCA make it the case that all oppressed agents have diminished autonomy. ${ }^{16}$

Removal of the presumption against paternalistic coercion of oppressed agents also makes it possible for SCA to promote such coercion in a second, more specific way. If autonomy is constituted partly by options provided by social conditions - as SCA state it is - autonomy can actually be enhanced, or provided for the first time, through coercion.

SCA are in fact interpreted in practical contexts as supporting paternalistic coercion that worsens the lives of the oppressed. The editors of a recent collection on autonomy summarize the upshot of SCA for social science as follows: "According to [relational autonomy views], when women make 'bad' or 'illiberal choices" because of the limited opportunities, "their decisionmaking is considered not truly autonomous. Consequently, some infer their choices are not to be respected" (Foblets, Graziedei et al. 2018). Uma Narayan (2002: 428429) argues that proponents of coercive policies against putatively oppressive

contemporary conceptual engineering literature. See, for example, Plunkett and Cappelen (2019).

16 On many conceptions of internalist procedural autonomy, oppressed agents are particularly likely to lack autonomy because they were not encouraged to develop requisite reflective or imaginative capacities (see Meyers 1989 and Friedman 2003, 179-205). On these views the autonomy deprivations of oppressed agents come about for contingent empirical reasons - it is not a part of these conceptions of autonomy itself that these agents have diminished autonomy. 
cultural practices, such as veiling, often claim that third-world women's lack of options diminishes the respect-worthiness of their choices.

Some SCA advocates bite this bullet. Oshana explicitly argues that "strong paternalistic intervention is sometimes needed to preserve the autonomy that is threatened by a competent and deserving person's self-regarding conduct" (20016: 115). However, SCA defenders might attempt to resist the implication that SCA justify paternalistic coercion. One way they might do so is by claiming that SCA only hold that opportunities - as opposed to compulsion to act or function in any particular way - are autonomy-enhancing. This is the view Stoljar develops in her (2014) response to criticisms of substantive conceptions of autonomy I make in earlier work (Khader 2011). Stoljar argues that substantive autonomy theorists need not constrain the content of individual choices. Instead, Stoljar claims, they can focus on social constitutivity and say that women need "freedom to do otherwise" than follow oppressive norms, without saying women should be coerced into rejecting them. But this defense of SCA is either ad hoc or dissolves into a defense of a nonconstitutive enabling conception of the type that I argued against above. It dissolves into a nonconstitutive conception if it argues against coercion on the grounds that the ability to choose whether to engage in opportunities helps autonomy only by enabling critical reflection.

To see why claiming that SCA only entail promoting opportunities might be ad hoc, note that the claim that opportunities are constitutive of autonomy is usually motivated by a perfectionist claim about the capacities exercised in an autonomous life - in Stoljar's case, a perfectionist claim about what a feminist life looks like, followed by the claim that it is impossible to live such a life absent the relevant opportunities. ${ }^{17}$ But if exercising the capacity is part of an autonomous life, it seems strange to claim that autonomy is conferred by having the opportunity to exercise the capacity rather than actually exercising it. The typical argument for not coercing people into taking advantage of opportunities is respect for autonomy, but SCA define autonomy so that this argument

17 There is another possible nonperfectionist line of reasoning that might seem to permit Stoljar's claim that opportunities are constitutive of autonomy. Rather than saying that autonomy requires leading a feminist life (or on the nonconstitutive interpretation, that options can make it more likely that one will lead a feminist life by making one more reflective, critical, etc.), she might be claiming that agents need to have the possibility to act in more than one way to count as autonomous. This seems plausible, but it would justify only an extremely minimal form of social constitutivity where agents always needed exactly two options. Stoljar's idea that oppressed agents need to be able to contravene oppressive social norms involves a more expansive notion of opportunity - even if the phrase "freedom to do otherwise" conceals it. 
is unavailable. The defender of SCA might try to make this argument available by claiming that autonomy is hybrid, including external social elements and internal elements - and that focusing on opportunities helps foster the internal elements. Again, I will say more about this type of view in the section on internally differentiated hybrid conceptions below, but for now I simply remark that, without an argument for why we should weight the internal elements of autonomy more heavily than living an autonomous life by taking advantage of valuable opportunities, this, too is ad hoc.

Another problem with the argument that SCA justify opportunities, not coercion, is that, because of collective action problems, many opportunities are best secured through coercion. The opportunity not to have rubella, for example, is best secured by coercive vaccination. Since oppressive social norms are often held in place by widespread compliance, and since individual agents who fail to comply stand to incur costs, changing them require a high level of coordination. This is precisely what the empirical literature on social norm change suggests (Mackie and Lejeune 20og; Paluck and Ball 2010). As Clare Chambers argues in a feminist philosophical application of the social norms literature, the opportunity not to be expected to have large breasts may be best supported by banning breast implants (Chambers 2004: 25-26).

A second way SCA defenders may resist the implication that SCA justifies paternalistic coercion is by distinguishing the concept they are trying to define from the one that guarantees freedom from coercion. Catriona Mackenzie (2014) takes this route and states that rationality rather than autonomy grounds the entitlement to freedom from coercive paternalism; Natalie Stoljar (2014) takes it, claiming that the relevant concept is harm; Oshana (2006) takes it at some points, arguing that the relevant concept is negative freedom. SCA defenders might also claim that there are two levels of autonomy, a minimal one that guarantees freedom from coercion and a more one that SCA embody (see Oshana 2006:100).

Yet the underlying reason liberals, such as Mill (Mill 2008), usually give for the harm principle is that coercion interferes with people's abilities to live autonomous lives. ${ }^{18}$ Negative freedom is usually thought of as a way of

18 Stoljar acknowledges this, saying that harm derives its importance for liberals "in part [from]respect for the value of autonomy" (250). But if the justifiability of coercion derives from the particular badness of harm, and the particular badness of harm derives from its unique ability to outweigh the importance of autonomy, it is unclear how the claim that autonomy judgments do not entail judgments about the justifiability of paternalistic coercion is tenable. Stoljar then goes on to offer a version of Raz's autonomy-based criticism of coercion, claiming that coercion usually limits the ability to engage in other autonomous pursuits. However, the tragic situation of oppressed agents is one where coercion is likely to 
operationalizing respect for autonomy; noninterference is rarely regarded as valuable for its own sake. Usage on its own of course does not settle the question of what autonomy is for. However, absent another explanation of the theoretical role of autonomy, and absent another freestanding coercion-limiting concept, the susceptibility of the oppressed to paternalistic coercion depends on how we define autonomy.

A third way SCA defenders try to defend against the claim that SCA licenses paternalistic coercion is to claim that there are two levels of autonomy and only one, the one that is irrelevant to paternalistic treatment, is socially constitutive (is Mackenzie 2014). It seems plausible, but without further explanation, that this splitting of autonomy also seems ad hoc. Since they proliferate concepts of autonomy, it is incumbent on defenders of SCA who split autonomy into two concepts to explain what theoretical value is added by calling external social conditions "autonomy," when we already have the concept of opportunity and other adjacent concepts - especially given the multiple theoretical downsides I have discussed. Further, coercion is not the only paternalism-related cost made acceptable by sca. I have already given an argument about asymmetrical susceptibility to paternalism, and I am about to argue that coercion is not the only cost that can be justifiably minimized in the name of SCA.

\subsection{Obscuring the Costs of Opportunity Enhancement}

I have argued that feminists should want a concept of autonomy that avoids imposing unacceptable costs on the oppressed. ${ }^{19}$ Some of the costs oppressed people stand to incur through attempted social change are costs to their abilities to live consistently with their own values. Feminists should want a concept of autonomy that sensitizes us to these costs for two reasons. First, people's ability to live types of lives they care about is itself a good, one whose diminution should matter in the social calculus about what to do. Second, losses to self-governance also often track other types of costs, especially under nonideal conditions. Oppressed people are often attached to certain ways of being and doing because they contribute to their well-being. Yet because of the tragic structure of oppressed agents' options, the links between these ways of being and doing and well-being are not always evident to an outsider. Valuing the first-person perspectives of the oppressed is often the only way to get a handle on how feminist political strategies will affect their well-being.

increase access to the activities that an aspirational socially constitutive conception take to be part of autonomy.

19 I have argued elsewhere (Khader 2011, 2013) that the fact that oppressed agents sometimes adapt their preferences or internalize their oppression does not constitute an argument not to afford them epistemic privilege about the facts about their own situations. 
SCA cannot assign distinctive importance to oppressed people's claims that their abilities to live in ways they care about have been reduced by feminist strategies. Because scA hold that deliberative capacities and opportunities are two parts of a single good, they suggest that losses to what people care about can be compensated for by new opportunities - even when these opportunities are imposed against people's wills. This is a problem unique to SCA because only scA claim that opportunities are part of the same good as (as in hybrid internal/external conceptions like Oshana's, Mackenzie's and Stoljar's), or should take the theoretical place of (as in Gauthier-Chung's conception), self-governance. Arguments that new opportunities can compensate for lost self-governance recur in defenses of SCA (see Oshana 2006; Nussbaum 1999). For example, Martha Nussbaum responds to the claim that it violates the autonomy of the poor to give them options they do not want that "choice is not pure spontaneity" and that "concern with flourishing is a better way of promoting choice than the liberal's narrow concern with autonomy alone" (Nussbaum 1999: 50). If Nussbaum only means that opportunities increase the range of available choices, this statement is noncontroversial but trivial. But she suggests much more than this, namely: that we need not worry about decreasing the autonomy of the oppressed by giving them opportunities they do not want, since opportunities increase autonomy.

This line of reasoning undercuts the possibility that something distinctive is lost when a person loses opportunities she cares about. Lack of attention to what oppressed people care about in turn desensitizes us to their objections to strategies for feminist change. Suppose for example that Lydia has become so attached to straightening her hair, shaping her body according to sexist and racist norms, and acting agreeably that she now enjoys the practices. Removing her opportunity to engage in them, though it might increase women's and people of color's options in the long term, involves taking away something she cares about. To overlook her actual desires and claim that her ability to do what she desires will be increased by removing the opportunity to engage in these practices risks rendering invisible the ways her interests in the actual world hinge on beauty and agreeableness.

The idea that self-governance costs can be compensated by opportunities encourages us to overlook harms to oppressed people's senses of self even when they are direct proxies for objective well-being. Changes to social conditions can produce what Meyers (2012), borrowing terminology from psychology, calls "identity conflict crises." These occur when changes in circumstances cause conflicts within an individual's practical identity that make it impossible for them to act in a way that is not self-betraying. Imagine Lydia values both acting in her own interests and acting morally. Under oppressive circumstances, engaging in beautification and practicing agreeableness, while believing it is 
praiseworthy not to "sweat the small stuff" allows her to meet both goals. In a changed world where opposition to sexism is socially rewarded and considered praiseworthy, her commitments to acting morally and promoting her interests will come apart. To maintain a coherent sense of self, Lydia must "shed" at least one commitment, but each may be so central to her sense of self that she experiences confusion about what she really desires or how to act in a way consistent with those desires.

Since SCA permit the conclusion that Lydia's new opportunities are autonomy-enhancing irrespective of how she feels, they fail to supply theoretical resources for seeing her as having been harmed. Of course, the fact that people who have internalized their oppression may lose the ability to live according to oppressive norms is not decisive against social change. But given that we have choices about how feminist social change should be pursued, and that we live under nonideal conditions where it is difficult for those with power to see what is at stake for those who lack it, we should resist moral concepts that obscure genuine burdens on the oppressed (see Khader 2018: 71-75). Seeing such burdens for what they are can be useful when choosing among strategies for change, and for assessing just how effective strategies for change are likely to be.

\subsection{An Objection from Internally Differentiated Hybrid Conceptions}

Proponents may defend SCA against my concerns about excessive paternalism tolerance by offering conceptions that distinguish internal and external elements of autonomy. Most existing SCA do take autonomy to have internal components as well as external ones. For example, Catriona Mackenzie (2014) develops an internally differentiated hybrid conception of autonomy to respond to claims I made in earlier work (2011) about how substantive and socially constitutive conceptions of autonomy lead to paternalism. Mackenzie delineates three axes within autonomy, self-governance, self-authorization, and self-determination. Opportunities are part of the self-determination axis. According to Mackenzie, distinguishing these axes prevents sCA from suggesting that it is acceptable to override people's wills to provide opportunities. She holds that political strategies motivated by an internally differentiated socially constitutive conception can pinpoint the specific elements of autonomy oppressed people lack and focus on changing those (Mackenzie 2015: 63).

Internal differentiation successfully avoids the conclusion that opportunities and self-governance are identical, but merely distinguishing the axes is not enough to justify opposition to imposing opportunities on those who do not want them. To avoid minimizing or erasing the costs of imposing opportunities, an internally differentiated concept of autonomy must say something about how the various axes should be weighted, how they are incommensurable 
with one another, or how the different axes accrue differently to members of different social groups. This leaves the defender of internally differentiated SCA who wishes not to obscure the costs of imposing opportunities with two options. First, they can weight the axes of autonomy differently and say that preserving self-governance trumps enhancing self-determination. This response is logically possible, but it seems at best $\mathrm{ad} \mathrm{hoc} \mathrm{and} \mathrm{at} \mathrm{worst} \mathrm{internally}$ inconsistent; if both are parts of autonomy, why give self-governance the special weight it needs to produce circumspection about paternalism? The answer would seem to have to do with some special conceptual relation between deliberative capacities and the right to determine the course of one's life. Yet it is unclear how to do this without resorting to a claim that self-governance is the true core of autonomy.

Second, though I am unaware of any defender of SCA who claims this, the defender of internally differentiated SCA might claim that the oppressed are advantaged with respect to internal capacities constitutive of autonomy. Whether this is true is an empirical question. However, it seems unlikely that cognitive and imaginative capacities and the willingness to engage in self-reflection systematically accrue in greater degrees to oppressed individuals. The closest thing to a feminist argument that members of oppressed groups possess superior internal autonomy competencies is the familiar standpoint theoretical argument that, because of conflicts between their self-valuing projects and the unjust social order, oppressed agents are especially likely to develop critical attitudes. However, being able to negatively appraise the social order is not the same thing as being able to think and act for oneself.

Even if an argument for the distinctive importance of self-governance within internally differentiated hybrid conceptions were forthcoming, there would be significant theoretical and practical downsides to adopting them. First, they are less parsimonious than competing internalist conceptions. The lack of parsimony would have to be justified by enhanced explanatory value. As I have mentioned at a number of points, it is unclear what is added by calling opportunities elements of autonomy, especially when most liberal theories take the presence of opportunities to be a good. The judgment that oppressed agents are harmed by lacking opportunities is readily available without the additional claim that opportunities constitute autonomy. Furthermore, the ability of internally differentiated SCA to function as character ideals would also still be subject to all of my earlier criticisms; multiplying vectors of SCA does nothing to change the problems with treating them as prescriptive character ideals under nonideal conditions.

Additionally, though I have cautioned against relying too heavily on conceptual analysis and intuitions, hybrid conceptions have some counterintuitive 
implications - including that a person's self can exert a "determining" force independently of her will. Consider a case where an oppressed agent accidentally thwarts an oppressive social order's ability to curtail her opportunities. Imagine, for example, that a girl takes an advanced math class that sexism caused her to be excluded from, not because she aimed to enter the class anyway, but because she was mistaken about the room number. Hybrid SCA counterintuitively suggest that taking the course unintentionally was an exercise of her autonomy.

A final reason to avoid proliferating components of autonomy is political. I have already mentioned a number of autonomy arguments that function in real-world political practices to justify hard paternalism toward oppressed agents. The reasoning behind these policies is that, since people who inhabit bad social conditions lack autonomy, the presumption for taking their wills as decisive recedes. Though hybrid internally differentiated concepts do not logically require this application, concerns about the political function of autonomy judgments in our actual world militate in favor of drawing a bright line between social conditions and deliberative capacities (see Khader 2011, Gauthier-Chung 2017b). Since attributions of autonomy and nonautonomy are typically seen as entailing views about the deliberative capacities of their objects, we should be wary of conceptions of autonomy that attribute diminished autonomy to the oppressed - as SCA by definition do. Though such political effects are not on their own decisive, many feminist philosophers argue that they are relevant to which concepts we should adopt. When combined with lack of parsimony, lack of added explanatory value, and counterintuitive implications, the political implications of SCA suggest a reason to avoid adopting them.

I have shown that SCA, when placed in two common theoretical roles for autonomy, yield (what feminists should take to be) perverse prescriptions about what to do in our nonideal world. These perverse prescriptions are generated by idealizing content in feminist SCA. Feminist SCA that could serve the roles of character ideal and paternalism-limiting concept make the presence of idealized social conditions a requirement of autonomy. As a result, the character ideals generated by socially constitutive autonomy ask agents to act as though very real obstacles are absent, and thus ask oppressed agents to sacrifice themselves or aggravate the oppression of their groups. Plugging SCA into the role of paternalism-limiting concept offers moral reasons to ignore oppressed agents' views 
about how their own lives should go. Since feminist philosophy aims to develop moral and political concepts that guide action in ways that reduce oppression, these perverse prescriptions are a problem.

Much more is at stake in the feminist task of defining autonomy than whether we can vindicate the intuition, held by some, that the unjust option restriction caused by oppression limits autonomy. The implications of adopting sCA I have developed in this paper suggest either that there are theoretical and political reasons to reject these intuitions or that defenders of SCA should offer an alternative theory of autonomy's role. SCA defenders need to say more about the theoretical value added by claiming that are opportunities part of autonomy, especially since the idea that lack of opportunity harms the oppressed is easy to vindicate without this claim, and since the link between autonomy and character becomes tenuous with it. Feminist theorizing about autonomy needs to take the theoretical roles of autonomy more seriously, and do so in ways that are attentive to how our theories allocate burdens to the oppressed.

\section{Acknowledgements}

I am grateful for comments on this paper from audiences at the Yale Moral Philosophy Working Group, the Fordham Workshop in Social and Political Philosophy, as well as from Maud Gauthier-Chung, Matt Lindauer, and Rosa Terlazzo.

\section{Biographical Note}

Serene J. Khader is Associate Professor of Philosophy at the CunY Graduate Center and Jay Newman Chair in Philosophy of Culture at Brooklyn College. She is the author of Adaptive Preferences and Women's Empowerment (Oxford 2011) and Decolonizing Universalism (Oxford 2018) as well as a number of articles.

\section{References}

Cappelen, H, and Plunkett, D. (2019) A Guided Tour of Conceptual Engineering and Conceptual Ethics. In Conceptual Engineering and Conceptual Ethics.

Chambers, C. (2004). "Are Breast Implants Better than Female Genital Mutilation." Critical International Journal of Social and Political Philosophy 7(3):1-33.

Christman, J. (2004). "Relational Autonomy, Liberal Individualism, and the Social Constitution of Selves." Philosophical Studies 117(1): 143-164. 
Collins, P.H. (2000). Black Feminist Thought. New York, Routledge.

Crenshaw, K. (1991). “Mapping the Margins.” Stanford Law Review 43(6): 1241-1258.

Dworkin, G. (1988). The Theory and Practice of Autonomy. Cambridge, Cambridge University Press.

Foblets, M.-C., M. Graziedei and A.D. Renteln (2018). Personal Autonomy in Plural Societies. London, Routledge.

Friedman, M. (2006). Autonomy, Gender, Politics. New York, Clarendon Press.

Gauthier-Chung, M. (2017a). "Hounded Women: The IPV Protocol and the Autonomy of Abuse Victims." Moral Philosophy and Politics 4(1): 67-85.

Gauthier-Chung, M. (2017b). Relational Autonomy from A Political Perspective. PhD, London School of Economics.

Khader, S.J. (2011). Adaptive Preferences and Women's Empowerment. Oxford, Oxford.

Khader, S.J. (2012). “Does Theorizing About Adaptive Preferences Deny Women's Agency?" Journal of Applied Philosophy 29(4): 302-317.

Khader, S.J. (2018). Decolonizing Universalism: A Transnational Feminist Ethic. New York, Oxford.

Laborde, C. (2008). Female Agency and the Critique of Republican Paternalism.

Lindauer, M. "Experimental Philosophy and the Fruitfulness of Normative Concepts". Philosophical Studies (2019). https://doi.org/10.1007/s11098-019-01302-3.

Lugones, M. (2003a). Structure/Anti-Structure and Agency Under Oppression. Pilgrimages/Peregrinajes. Lanham, MD, Rowman and Littlefield.

Lugones, M. (2003b). Tactical Strategies of the Streetwalker/Estrategias Tacticas de La Callajera. Pilgrimajes/Peregrinajes. Lanham, MD, Rowman and Littlefield: 207-238.

MacKenzie, C. (2008). “'Relational Autonomy, Normative Authority and Perfectionism”." Journal of Social Philosophy 39: 512-533.

Mackenzie, C. (2015). Responding to the Agency Dilemma: Autonomy, Adaptive Preferences, and Internalized Oppression. Personal Autonomy and Social Oppression: 48-68.

Mackie, G. and J. Lejeune (2009). Social Dynamics of Abandonment of Harmful Practices. Innocenti Working Paper, UnICEF.

MacKinnon, C. (1991). Towards a Feminist Theory of the State. Cambridge, Harvard University Press.

Madhok, S., A. Phillips and K. Wilson (2013). "Introduction". Gender, Agency, and Coercion.

Mahmood, S. (2005). Politics of Piety. Princeton, NJ, Princeton University Press.

Meyers, D. (1991). Self, Society, and Personal Choice. New York, Columbia.

Meyers, D. (200oa). "Feminism and Women's Autonomy: The Challenge of Female Genital Cutting." Metaphilosophy 31(5): 469-491.

Meyers, D. (200ob). Intersectionality and the Authentic Self: Opposites Attract. Relational Autonomy. C. Mackenzie and N. Stoljar. New York, Oxford:151-181. 
Meyers, D. (2012). "Psychocorporeal Selfhood, Practical Intelligence and Autonomy." Autonomy and the Self. Michael Kühler \& Nadja Jelinek (eds.). The Netherlands, Springer.

Meyers, D.T. (1987). "'Personal Autonomy and the Paradox of Feminine Socialization”." The Journal of Philosophy 84(11): 619-628.

Mill, J.S. (2008). On Liberty and Other Essays. Oxford, Oxford University Press.

Mills, C. (2005). "Ideal Theory as Ideology." Hypatia 20 (3): 165-184.

Mills, C. and C. Pateman (2007). Contract and Domination. Boston, Polity.

Narayan, U. (2002). "Minds of Their Own: Choices, Autonomy, Cultural Practices, and Other Women”. A Mind of One's Own: Feminist Essays on Reason and Objectivity L. M. A. a. C. E. W. Boulder. Boulder, Colorado, Westview.

Noggle, R. (2011). "Review of Personal Autonomy in Society." Journal of Value Inquiry 45(2): $3^{-25}$.

Nussbaum, M.C. (1999). Sex and Social Justice. Oxford, Oxford University Press.

Oshana, M. (1998). "Personal Autonomy and Society." Journal of Social Philosophy 29(1): $81-102$.

Oshana, M. (2006). Personal Autonomy in Society. New York, Routledge.

Oshana, M. (2015). Is Social-Relational Autonomy A Plausible Ideal. Personal Autonomy and Social Oppression. M. Oshana. New York, Routledge.

Paluck, E.L. and L. Ball (2010). Social Norms Marketing Aimed at Gender-Based Violence, International Rescue Committee.

Plunkett, David (2019). Normative Roles, Conceptual Variance, and Ardent Reasoning About Normativity. Inquiry 1-26.

Raz, J. (1988). The Morality of Freedom. Oxford: Clarendon Press.

Sen, A. (2009). The Idea of Justice. Cambridge, Harvard.

Sperry, E. (2013). "Dupes of Patriarchy: Strong Substantive Autonomy's Epistemological Weakness." Hypatia 28(4): 887-904.

Stoljar, N. (2000). "Autonomy and the Feminist Intuition". Relational Autonomy: Feminist Perspectives on Autonomy, Agency, and the Social Self. C.M. a. N. Stoljar. Oxford, Oxford University Press: 94-111.

Stoljar, N. (2014). Autonomy and Adaptive Preference Formation. Autonomy, Oppression, and Gender. A. Veltman and M. Piper. New York, Oxford.

Walker, M.U. (2007). Moral Understandings. New York, Oxford.

Westlund, A. (2003). "Selflessness and Responsibility for Self." The Philosophical Review $112(4)$.

Wolf, N. (2002). The Beauty Myth. New York, Anchor Doubleday.

Young, I. (1991). Beyond the Distributive Paradigm. Justice and the Politics of Difference: 15-33. 